\title{
Procedimentos de Gerenciamento de Resíduos de Empresas sob a Ótica da Institucionalização dessas Práticas ${ }^{1}$
}

\section{Procedures for Waste Management of Companies from the Perspective of Institutionalization of these Practices}

\author{
Ana Carolina Vasconcelos Colares \\ Endereço: Pontifícia Universidade Católica de Minas Gerais \\ Professora Assistente do Departamento de Ciências Contábeis \\ Rua Walter Ianni, 255, São Gabriel, CEP: 31.980-110, Belo Horizonte-MG \\ E-mail: carolinacolares@pucminas.br \\ Márcia Athayde Matias \\ Endereço: Universidade Federal de Minas Gerais \\ Professora Adjunta do Departamento de Ciências Contábeis \\ Av. Presidente Antônio Carlos, 6627, Pampulha, CEP: 21.270-010, Belo Horizonte-MG \\ E-mail: mathayde@face.ufmg.br
}

RESUMO

Em se tratando de meio ambiente, as empresas surgem como consideradas grandes poluidoras, e um dos temas principais discutidos em gestão ambiental é a questão dos resíduos, uma vez que através da gestão adequada dos resíduos a empresa é capaz de integrar desempenho ecológico e econômico. Essa questão já foi percebida e nesse sentido é claro o processo de institucionalização das práticas ambientais. Desta forma, surge o seguinte questionamento: é possível perceber a institucionalização dos procedimentos de gerenciamento de resíduos observados em empresas da região de Belo Horizonte? O estudo é classificado como descritivo e bibliográfico, que por meio de uma pesquisa survey foram levantadas informações sobre tais procedimentos de gerenciamento de resíduos de uma amostra de 31 empresas situadas no município de Belo Horizonte-MG. Percebeu-se que a prática de reciclagem visando reduzir a geração de resíduos e de materiais que não podem ser reciclados como a mais sedimentada na prática empresarial. Baseado nos achados da pesquisa, conclui-se que as empresas da amostra estão claramente em um progresso moderado de sedimentação de práticas voltadas para a sustentabilidade empresarial, no que se refere ao gerenciamento dos resíduos, portanto, a institucionalização dessas práticas ainda se encontra em andamento.

Palavras-chave: Gerenciamento de resíduos; Sustentabilidade empresarial; Institucionalização de práticas ambientais.

\section{ABSTRACT}

When it comes to the environment, companies emerge as considered major polluters, and one of the main themes discussed in environmental management is the waste issue, since through proper waste management company is able to integrate ecological and economic performance. This issue has been perceived and the process of institutionalization of environmental practices is clear. Thus, the following question arises: is it possible to realize the institutionalization of procedures for waste management observed in companies from Belo Horizonte region? The study is classified as descriptive and bibliographic, which through a survey research was raised information about such procedures for managing waste from a sample of 31 companies located in the city of Belo Horizonte-MG. It was felt that the practice of recycling to reduce waste generation and

\footnotetext{
${ }^{1}$ Artigo recebido em 25.01.2013. Revisado por pares em 10.03.2013 (blind review). Reformulado em 25.03.2013. Recomendado para publicação em 29.03.2013 por José Ribamar Marques de Carvalho (Editor Científico). Publicado em 01.04.2013. Organização responsável pelo periódico UACC/UFCG.
} 
material that cannot be recycled as the most established business practice. Based on the research findings, it is concluded that companies in the sample are clearly at a moderate progress of sedimentation of these practices for corporate sustainability. In relation to waste management, therefore, the institutionalization of these practices is still in progress.

Key Words: Waste Management; Corporate Sustainability; Institutionalization of environmental practices.

\section{INTRODUÇÃO}

O termo sustentabilidade está cada vez mais disseminado nos dias atuais e muito se discute sobre tornar o crescimento, a produção e o consumo mais sustentáveis, considerando os efeitos climáticos e ambientais. Nesse sentido, Brundtland et al. (2012) entendem que tais mudanças exigem reconhecimento, compreensão e ações sobre as interconexões entre a economia, a sociedade e o ambiente natural.

Em se tratando de economia, as empresas surgem como consideradas grandes poluidoras do meio ambiente, e um dos temas principais discutidos em gestão ambiental é a questão dos resíduos (KING et al, 2006; PONGRÁCZ, 2009), uma vez que através da gestão adequada dos resíduos a empresa é capaz de integrar desempenho ecológico e econômico (VELLANI e RIBEIRO, 2009). Essa questão já foi percebida e nesse sentido é claro o processo de institucionalização das práticas ambientais.

Há discussões sobre a institucionalização de práticas voltadas para o desenvolvimento sustentável, o qual foi definido pela Comissão Mundial sobre Meio Ambiente e Desenvolvimento (World Comission on Environmental and Development WCED) através do Relatório de Brundtland como a forma de desenvolvimento que satisfaz as necessidades presentes, sem comprometer a capacidade das gerações futuras de suprir suas próprias necessidades (WCED, 1987). A relevância de se discutir a institucionalização das práticas ambientais, focadas nessa pesquisa nas práticas de gerenciamento de resíduos, se dá pelo fato de que a gestão ambiental é uma forma de materialização do desenvolvimento sustentável (SEIFFERT, 2009).

Considerando que visto que Guerreiro, Frezatti e Cansado (2006) consideram a instituição como conjunto de rotinas desempenhadas de forma habitual por um grupo de indivíduos, a questão que norteia essa pesquisa é: é possível perceber a institucionalização dos procedimentos de gerenciamento de resíduos observados em empresas da região de Belo Horizonte? Sendo assim, tem como objetivo realizar uma análise empírica em empresas que possuem potencial de geração de resíduos, a fim de observar evidências de institucionalização de suas práticas de gerenciamento desses resíduos, ou seja, quais procedimentos as empresas vêm adotando de forma sedimentada, tendo sido incorporados às operações normais da empresa.

A pesquisa se justifica por trazer uma discussão voltada ao meio ambiente buscando identificar como estão ocorrendo as práticas de tratamento de resíduos, o 
que é especialmente importante para a preservação do meio ambiente e o desenvolvimento sustentável, e tende a se sedimentar como prática usualmente aceita pelas empresas.

\section{REFERENCIAL TEÓRICO}

Esta seção se dispõe a apresentar uma revisão de literatura no sentido de dar um embasamento teórico à pesquisa e auxiliar a alcançar os objetivos propostos. Desta forma, inicialmente é apresentado o processo de institucionalização das práticas gerenciais ambientais e depois se trata das formas de tratamento e gerenciamento de resíduos, que são objetivo de pesquisa deste estudo.

\subsection{Processo de Institucionalização das Práticas Gerenciais Ambientais}

Diante dos objetivos desta pesquisa, faz-se conveniente tratar do processo de institucionalização sob a perspectiva gerencial voltada para as práticas ambientais. Para Nobre e Amazonas (2002, p. 8), “[...] a noção de desenvolvimento sustentável só conseguiu se tornar pervasiva e universalmente aceita [...] porque conseguiu reunir sob si posições teóricas e políticas contraditórias e até mesmo opostas". Em outras palavras, os autores definem que o conceito é o ponto de partida para a institucionalização da problemática ambiental (NOBRE e AMAZONAS, 2002).

Nesse sentido, para realizar o processo de institucionalização do conceito de desenvolvimento sustentável em uma organização empresarial deve haver o compromisso da gestão alinhado com as missões específicas do negócio (WEILER et al, 2005). Para os autores, são necessárias mudanças culturais em toda a empresa, além de adotar políticas de avaliação de risco de novos produtos os quais sua vida útil será questionada de acordo com as análises de benchmarking (WEILER et al, 2005). Weber et al (2009) apoiam essa ideia ao afirmarem que a "[...] institucionalização das normas e políticas sustentáveis requer uma compreensão abrangente de como funciona a organização de visão, decisão, do ponto de aplicação ${ }^{2 \prime \prime}$. Da mesma forma, Tinoco e Kraemer (2008) afirmam que a mudança organizacional é inevitável para que a empresa passe a realmente trabalhar com gestão ambiental, além de passarem por uma revisão de seus paradigmas.

Além de discutir a institucionalização de conceitos, é também importante entender as razões que levam os gerentes a se interessarem pela gestão ambiental em busca de vinculá-las ao processo de institucionalização. Burrit e Saka (2006), por exemplo, corroboram com o processo destacando algumas razões as quais evidenciam essa tendência: além da legislação ambiental, os autores afirmam haver

\footnotetext{
${ }^{2}$ Institutionalization of sustainable standards and policies requires a comprehensive understanding of how the organization works from vision, to decision, to point of implementation.
} 
uma promoção das práticas de gestão ambiental por meio de órgãos governamentais e algumas instituições educacionais com o objetivo de identificar os melhores casos práticos como base para sua implementação.

Destaca-se ainda que, conforme Tolbert e Zucker (1999), o número de organizações que adotam os conceitos e práticas voltadas ao meio ambiente e os impactos dessa adoção são determinantes no processo de institucionalização. Segundo a Teoria Institucional, para que determinada estrutura se institucionalize, faz-se necessário analisá-la, avaliá-la e evidenciar seus impactos. Nesse sentido se destacam os três estágios de institucionalização e as principais características de cada estágio, sendo o primeiro estágio o pré-institucional, o qual tem como característica a habitualização dos processos, o segundo estágio, denominado estágio semiinstitucional, o qual tem como característica a objetivação dos processos e o terceiro estágio, denominado de total institucionalização, caracterizado pela sedimentação dos processos e plena utilização por parte das empresas (TOLBERT e ZUCKERT 1999).

Voltando a questão ambiental, com base nas pesquisas mencionadas nesta subseção (HEDIGER, 1997; SEIFFERT, 2009; WEILER et al, 2005; WEBER et al, 2009; PRAKASH, 1999; VILLIERS e STADEN, 2010), é possível realizar algumas considerações acerca do processo de institucionalização presente na implantação de uma gestão ambiental. Em primeiro lugar, o processo institucionalista abriga um amplo leque de diversidade entre autores e proposições, o que faz com que esta corrente haja uma carência de coesão teórica (NOBRE e AMAZONAS, 2002). Por outro lado, "[...] é possível identificar na literatura institucionalista certos elementos amplamente utilizados que podem ser entendidos como elementos de uma base teórica comum, cujo desenvolvimento pode conduzir a uma maior coesão teórica desta corrente" (NOBRE e AMAZONAS, 2002, p. 155). Nesse sentido, encontram-se evidências de um processo de institucionalização das práticas de gestão ambiental, mas ainda carecem de uma confirmação empírica.

Em segundo lugar, é importante ressaltar que a implantação de práticas ambientais e de uma postura sustentável depende de diversos fatores internos à empresa, se destacando principalmente a convergência da missão da empresa com um forte ajuste à cultura organizacional (WEILER et al, 2005; WEBER et al, 2009; TINOCO e KRAEMER, 2008).

Em terceiro lugar, o processo de institucionalização ambiental não deriva somente das instituições governamentais, pressões de concorrentes e entidadesmodelo de gestão ambiental (tais como ISO 14000 e Responsible Care). Tal processo também é influenciado pela autonomia dos gestores os quais também podem influenciar nas políticas da empresa (PRAKASH, 1999).

Em quarto (e último) lugar, destacam-se as necessidades dos shareholders como principais interessados nas políticas organizacionais podendo influenciar 
diretamente os gestores por meio de suas demandas informacionais, as quais Villiers e Staden (2010) enfatizaram o disclosure ambiental como forte interesse desses usuários. Nesse sentido, verifica-se que o processo de institucionalização pode derivar de diversos fatores os quais em conjunto proporcionam a procura e necessidade de implantar práticas gerenciais por meio de uma gestão ambiental eficiente e transparente.

\subsection{Tratamento dos Resíduos}

Sob a ótica da sustentabilidade e da ecoeficiência empresarial, o maior foco de discussão é o tratamento dos resíduos, tendo em vista que as indústrias necessitam de matéria-prima para a produção de bens e esses processos de manufatura produzem lixo (KRAEMER, 2006). Além disso, a redução dos resíduos já vem sendo uma preocupação para várias empresas há algum tempo (WBCSD, 2000b) e tal ação pode reduzir a produção e o consumo alinhando com os objetivos da sustentabilidade.

Conforme Seiffert (2006) a produção de resíduos significa desperdício de matérias-primas e insumos, desta forma, as empresas são obrigadas a executarem outras atividades que adicionam custos ao processo e não criam valor para os clientes. Nesse sentido, a discussão sobre a produção e o gerenciamento dos resíduos se torna relevante para a consecução da pesquisa, observando ainda que os resíduos constituem um problema ambiental e o seu gerenciamento deve ser conduzido de forma adequada, seja pela sua disposição final ou pela reciclagem (NASCIMENTO e MOTHÉ, 2007).

Ao falar de tratamento dos resíduos, muitos conceitos aparecem para discutir a mesma ideia. Portanto é relevante para essa pesquisa conceituá-los. Na opinião de Pongrácz (2009), o resíduo (chamado de waste) é relativo a duas concepções: primeiro algo se torna resíduo quando perde sua função primária. Segundo, a noção de resíduos está relacionada com a questão tecnológica e a forma como foi gerada. Conforme o autor, para se definir os resíduos, deve-se focar na ideia por traz da razão do desperdício para que se possa ter uma percepção de como pode ser evitado. O desperdício está muito relacionado com a inovação tecnológica, no sentido de que há a redução dos resíduos sólidos na medida em que essa tecnologia se atualiza. “Em outras palavras, melhorias promovidas na capacidade tecnológica condicionam, mas não necessariamente determinam, o bom desempenho em termos de gerenciamento de resíduos sólidos nas empresas" (VIEGAS e FRACASSO, 1998, p. 41).

De acordo com a Lei 12.305/2010, que institui a Política Nacional dos Resíduos Sólidos, a definição dos resíduos sólidos indica ser qualquer:

[...] material, substância, objeto ou bem descartado resultante de atividades humanas em sociedade, a cuja destinação final se procede, se propõe 
proceder ou se está obrigado a proceder, nos estados sólido ou semissólido, bem como gases contidos em recipientes e líquidos cujas particularidades tornem inviável o seu lançamento na rede pública de esgotos ou em corpos d'água, ou exijam para isso soluções técnica ou economicamente inviáveis em face da melhor tecnologia disponível (BRASIL, 2010, art. $3^{\circ}$ ).

Corroborando com a ideia de Pongrácz (2009), a Lei 12.305/2010 discute que os resíduos sólidos também são gerados através da inviabilidade da tecnologia e acrescenta a questão econômica, visto que alguns resíduos são de difícil tratamento. Destaca-se também a definição da legislação como um bem descartado, o que colabora com a ideia de desperdício ou perda de sua função primária.

Outra percepção sobre a Lei 12.305/2010, é que os resíduos de forma geral são tratados como resíduos sólidos independentemente do estado físico em que se encontra, seja sólido, líquido ou gasoso. Por outro lado, o Centro Nacional de Tecnologias Limpas (CNTL) do SENAI-RS (2003) entende que o conceito de resíduos é mais amplo e definido como "[...] matérias-primas ou insumos não aproveitados ou desperdiçados nos processos produtivos", entendendo que os resíduos devem ser devidamente segregados e classificado nas formas sólida, líquida e gasosa (SENAIRS, 2003; KRAEMER, 2006).

Além da forma sólida dos resíduos, já discutida anteriormente, a sua classificação quanto à forma é também descrita conforme CNTL do SENAI-RS (2003) e BRAGA (2010):

- Resíduos Líquidos: Denominam-se efluentes industriais os quais provém de qualquer utilização da água para fins industriais e adquire características próprias em função do processo industrial empregado;

- Resíduos Gasosos: São as emissões atmosféricas, sendo qualquer substância (ou combinação de substâncias) presente na atmosfera, danosa ao bem-estar do ser humano e do meio ambiente.

Além da forma, os resíduos também podem ser classificados quanto à sua origem e periculosidade (BRASIL, 2010). Conforme a Lei 12.305/2010 há diversas fontes de origem dos resíduos, se destacando os resíduos urbanos (domiciliares e de limpeza urbana), resíduos, resíduos rurais, resíduos de serviços de saúde, resíduos da construção civil e resíduos de mineração. Com relação à periculosidade, os resíduos estão classificados em:

a) resíduos perigosos: aqueles que, em razão de suas características de inflamabilidade, corrosividade, reatividade, toxicidade, patogenicidade, carcinogenicidade, teratogenicidade e mutagenicidade, apresentam significativo risco à saúde pública ou à qualidade ambiental, de acordo com lei, regulamento ou norma técnica;

b) resíduos não perigosos: aqueles não enquadrados na alínea "a". (BRASIL, 2010, art. 13ํ). (BRASIL, 2010) 
Na opinião de Seiffert (2006), a redução na geração de resíduos para as empresas pode ser uma vantagem competitiva, visto que mesmo os pequenos resultados podem ter um impacto significativo nos processos industriais, principalmente quando se é um resultado recorrente para a empresa. Desta forma, a norma ABNT NBR ISO 14001/2004 recomenda que as organizações considerem aspectos que estejam associados a bens e serviços por ela utilizados, e serviços que ela forneça, incluindo entre outros aspectos, o gerenciamento dos resíduos (ABNT, 2004).

Destaca-se ainda, que na visão de Hu, Sheu e Haung (2002), a importância do gerenciamento dos resíduos passou a ser uma preocupação presente na administração das organizações por meio da pressão impulsionada pelos stakeholders, que acreditavam que a questão ambiental era uma variável inquestionável na prioridade dos gestores.

Considerando os conceitos anteriormente abordados sobre os resíduos e considerando sua relação com o gerenciamento dos resíduos, optou-se por considerar na definição dos resíduos aqueles que são gerados através das atividades industriais em sua natureza sólida, líquida ou gasosa, bem como aqueles que são considerados somente no final de sua vida útil, ou seja, os produtos que após utilização pelo consumidor final, deverão ter uma destinação final adequada de seus componentes residuais.

A seguir são tratados alguns procedimentos utilizados no gerenciamento dos resíduos com a finalidade de conceituá-los e apresentar as vantagens e benefícios de se utilizar cada uma das técnicas de gestão ambiental.

\subsection{Procedimentos de Gerenciamento de Resíduos}

Memon (2010) discute sobre o gerenciamento dos resíduos sólidos sob a abordagem dos $3 \mathrm{R}$ (reduzir, reutilizar e reciclar) como tendo o foco a otimização do tratamento dos resíduos em quaisquer setores potencialmente geradores. Ressalta-se ainda que as ações dos $3 \mathrm{R}$ são essencialmente preventivas, no entanto somente a redução dos resíduos pode de fato eliminar a geração, já que a reutilização e reciclagem ocorrem após a produção, mesmo que possuam a finalidade de dar uma destinação ecoeficiente aos resíduos gerados.

Sob o ponto de vista da legislação nacional tratada pela Lei 12.305 sobre a Política Nacional de Resíduos Sólidos, o gerenciamento ou tratamento dos resíduos podem ser vistos através da:

VII - destinação final ambientalmente adequada: destinação de resíduos que inclui a reutilização, a reciclagem, a compostagem, a recuperação e o aproveitamento energético ou outras destinações admitidas pelos órgãos competentes do Sisnama, do SNVS e do Suasa, entre elas a disposição final, observando normas operacionais específicas de modo a evitar danos ou 
riscos à saúde pública e à segurança e a minimizar os impactos ambientais adversos. (BRASIL, 2010, art, 3).

Ferreira (2007) afirma que as principais atividades da gestão ambiental contemplam a prevenção, recuperação e reciclagem, todas relacionadas com as atividades de produção, as quais estão diretamente vinculadas com o evento econômico-ambiental denominado degradação produzida. Considerando que a atividade de recuperação é uma ação reativa da empresa, somente são consideradas neste momento as atividade de prevenção e reciclagem.

As atividades de prevenção se referem à proteção ao meio ambiente da ação da poluição (FERREIRA, 2007), e podem-se definir iniciativas tais como estender a comercialização de produtos ou embalagens recicláveis, aprimoramento de sistemas produtivos, redução na emissão de resíduos (PAIVA, 2009). Além disso, o gerenciamento ambiental tem sido observado desde o início da década de 90 como ferramenta de competitividade (VIEGAS e FRACASSO, 1998), sendo portanto, uma necessidade ambiental e empresarial. Verifica-se, portanto, que tais ações proativas estão diretamente relacionadas aos princípios do WBCSD (2000b):

a) Redução da intensidade de materiais;

b) Redução da intensidade de energia;

c) Redução da dispersão de substâncias tóxicas;

d) Aumentar a reciclabilidade dos seus materiais;

e) Maximizar o uso de recursos renováveis;

f) Estender a durabilidade dos produtos;

g) Aumentar a intensidade dos serviços.

Desta forma, destaca-se que o foco maior das atividades de prevenção é justamente a redução dos insumos utilizados na produção, bem como da geração dos resíduos. No entanto, na percepção de Lilja (2009), quando se fala de prevenção de resíduos não se deve pensar em gerenciamento dos mesmos, e sim de uma política ambiental que pode ser chamada de consumo e produção sustentável ou política de produção mais limpa.

Dentre as formas de tratamento dos resíduos abordadas por Zamorano et al (2011), foram citadas a produção de energia, reciclagem ou outros tipos de valoração e a disposição em aterros. Ressalta-se que este último não é considerado como uma forma de gerenciamento dos resíduos, uma vez que é simplesmente descartado. No entanto, as demais formas de tratamento citadas pelos autores podem ser consideradas como tipos de gerenciamento de resíduos, já que têm a finalidade de reutilização seja como energia, matéria-prima ou subprodutos.

Paiva (2009, p. 29) corrobora ao afirmar que os cuidados com o meio ambiente “[...] compreendem não somente o tratamento dos resíduos gerados na produção, 
mas também o acompanhamento e a coleta dos descartes dos produtos quando do final do seu ciclo de vida, armazenando-os adequadamente ou ainda reciclando-os".

Nesse sentido, King et al (2006, p. 258) concordam haver quatro níveis estratégicos de destinação dos resíduos sólidos, quais sejam:

1. Redução do desperdício (assim como elevar a durabilidade do produto);

2. Reutilização de sobras (assim como remanufaturar produtos para uma segunda vida);

3. Recuperação dos resíduos (assim como reciclagem de matéria prima); e,

4. Aterro de lixo (como último recurso).

O último nível estratégico apresentado, ou seja, o uso do aterro de lixo significa dizer que, em uma economia sustentável essa hipótese só deve existir quando não houver mais nenhuma outra possibilidade de não desperdiçar. No caso das empresas, quanto menos utilizarem o aterro de lixo como opção, maior será o proveito dos recursos e menores serão os custos dos processos de produção (KING et al, 2006).

\subsubsection{Reaproveitamento de Resíduos e Fabricação de Subprodutos}

Quando se fala em reutilização ou reaproveitamento, alguns procedimentos e definições podem se encaixar na sua concepção dado o seu emprego no gerenciamento de resíduos. Desta forma, é relevante conceituar a reutilização de acordo com a Lei 12.305 sobre a Política Nacional de Resíduos Sólidos, a qual a define como "o processo de aproveitamento dos resíduos sólidos sem sua transformação biológica, física ou físico-química” (BRASIL, 2010, art. 3).

Destaca-se ainda, que o reaproveitamento pode ser realizado tanto como matéria-prima como também materiais secundários, e podem ser destinados à fabricação de subprodutos, que "decorrem de um processo de produção conjunto, e que apresentam quantidade ou valor relativamente baixo em comparação com os produtos principais" (MAHER, 2001). Tal gerenciamento vai ao encontro do segundo nível estratégico de destinação dos resíduos sólidos que trata da reutilização das sobras, conforme King et al (2006).

\subsubsection{Reciclagem}

Por outro lado, havendo essa transformação do resíduo, tem-se a reciclagem que também merece destaque maior por ser muito utilizada entre as indústrias. Desta forma, a Lei 12.305 é novamente citada para definir um conceito sobre reciclagem como o "processo de transformação dos resíduos sólidos que envolve a alteração de suas propriedades físicas, físico-químicas ou biológicas, com vistas à 
transformação em insumos ou novos produtos (BRASIL, 2010, art, 3)". Destaca-se ainda, que há possibilidade de utilizar o material reciclado como insumo da produção ou como um subproduto.

No entanto, quando se fala em reciclagem de materiais, duas abordagens distintas podem ser identificadas: na abordagem do conteúdo reciclado (por exemplo, o metal), este material é utilizado na fabricação de produtos, portanto, os impactos ambientais de beneficiamento, extração e refinação de metais primários são atribuídos somente ao primeiro uso desse material. A abordagem da reciclagem no final do ciclo de vida do produto considera a reciclagem no pós-consumo, a qual evita a produção do metal primário, e os impactos evitados são creditados para o produto que envia o metal para a reciclagem (FRISCHKNECHT, 2010).

Tais abordagens sugerem algumas observações a serem apontadas. A reciclagem é tratada em dois momentos distintos, os quais podem trazer a ideia de responsabilidade social, pois a empresa se preocupa em reduzir impactos ambientais e também em dar uma destinação final ao produto após o seu consumo. Além disso, destaca-se a abordagem gerencial do ciclo de vida dos produtos, a qual leva em consideração todas as fases da vida útil e seus impactos ao meio ambiente, inclusive após seu uso pelo consumidor final. Finalmente, destaca-se que ambas as abordagens de reciclagem podem ser consideradas como procedimentos que levam a ecoeficiência empresarial.

$\mathrm{Na}$ percepção de IBAM (2001), a reciclagem é um procedimento de gerenciamento dos resíduos que tem inúmeras vantagens, porém o beneficiamento correto desse material pelas indústrias é bastante oneroso. Tal fato tem provocado negligência por parte das indústrias que lidam com sucata, manipulando os materiais sem empregar tecnologia limpa de processamento (que têm um alto custo). O problema muitas vezes se refere à separação do material a ser reciclado, que deve ser realizado no momento de sua geração, pois sua contaminação pode comprometer o beneficiamento correto (IBAM, 2001).

Por outro lado, o processo de reciclagem traz vantagens tais como a preservação dos recursos naturais, economia de energia, economia de transporte (pela redução de material de demanda o aterro), geração de emprego e renda e conscientização da população para as questões ambientais (FIRJAN, 2006; IBAM, 2001).

\subsubsection{Compostagem}

Há ainda que se considerar o processo de compostagem dos resíduos, anteriormente citado pela Lei 12.305 (BRASIL, 2010, art. 3, inc. VII). Na percepção de IBAM (2001, p. 124), a compostagem se define "[...] como o processo natural de decomposição biológica de materiais orgânicos (aqueles que possuem carbono em 
sua estrutura), de origem animal e vegetal, pela ação de microorganismos". Nesse sentido, verifica-se que tal processo é mais comumente utilizado para tratamento de lixo doméstico, bem como resíduos de origem orgânica.

\subsubsection{Coleta seletiva}

A Lei Federal no 12.305/2010 define coleta seletiva como a "coleta de resíduos sólidos previamente segregados conforme sua constituição ou composição" (BRASIL, 2010). A coleta seletiva é um estágio intermediário entre a geração dos resíduos e o gerenciamento dos mesmos. Para as empresas que não dispõem de instalações para realizar tal gerenciamento, elas podem separar os materiais para terceirizar o serviço ou vender para empresas que realizam esse gerenciamento.

\subsubsection{Outros}

Em último caso, a disposição final dos resíduos em aterros deverá ser uma hipótese somente quando não houver mais nenhuma outra possibilidade de não desperdiçar os resíduos (KING et al, 2006). A Lei 12.305/2010 faz a devida menção a respeito da disposição final dos resíduos:

VIII - disposição final ambientalmente adequada: distribuição ordenada de rejeitos em aterros, observando normas operacionais específicas de modo a evitar danos ou riscos à saúde pública e à segurança e a minimizar os impactos ambientais adversos. (BRASIL, 2010, art, 3).

Infelizmente, muitas vezes a opção pela disposição final em aterros industriais é realizada pela vantagem de ter um baixo custo em relação às outras opções de tratamento, além de também poder ser utilizado para a grande maioria dos resíduos. No entanto, um aterro industrial deverá ter multissistemas que envolvam o constante tratamento e monitoramento dos resíduos e águas subterrâneas (FIRJAN, 2006).

Destaca-se ainda as formas de tratamento e gerenciamento dos resíduos geram uma discussão bastante extensa, devido aos vários procedimentos existentes e a ausência de consenso entre os autores sobre o tema (conforme visto na classificação dos procedimentos de tratamento e gerenciamento dos resíduos industriais). No entanto, a fim dar embasamento às práticas gerenciais de tratamentos dos resíduos, foi considerado o resíduo em seu sentido mais amplo, ou seja, desde a sua geração até o final do seu ciclo de vida.

\section{PROCEDIMENTOS METODOLÓGICOS}

O estudo se classifica como uma pesquisa do tipo descritiva, uma vez que possui o objetivo de realizar uma análise empírica em empresas de Belo Horizonte, a 
fim de observar evidências de institucionalização de suas práticas de gerenciamento desses resíduos. A pesquisa descritiva é caracterizada por "[...] descrever, narrar, classificar características de uma situação e estabelece conexões entre a base teóricoconceitual existente ou de outros trabalhos já realizados sobre o assunto" (CHAROUX, 2006, p. 39).

Com relação aos procedimentos da pesquisa, este artigo utiliza a pesquisa bibliográfica e de levantamento, como procedimentos para se atingir os seus objetivos. O levantamento ou survey é também utilizado na pesquisa e se caracteriza:

[...] pela interrogação direta das pessoas cujo comportamento se deseja conhecer. Basicamente, procede-se a solicitação de informações a um grupo significativo de pessoas acerca do problema estudado para em seguida, mediante análise quantitativa, obter as conclusões correspondentes aos dados coletados (GIL, 1999, p. 70).

O survey é aplicado nesta pesquisa com o intuito de solicitar informações sobre a geração e o gerenciamento de resíduos às empresas situadas em Belo Horizonte. A análise comparativa entre a revisão da literatura e a pesquisa empírica serve para fazer uma avaliação sobre como são essas práticas na teoria e identificar aquelas se encontram em um processo de institucionalização. Utilizou-se como critério para evidenciar como parte de um estágio total de institucionalização a sedimentação dos processos em pelo menos $70 \%$ de recorrência entre as empresas da amostra, visto que Guerreiro, Frezatti e Cansado (2006) consideram a instituição como conjunto de rotinas desempenhada de forma habitual por um grupo de indivíduos. Nesse sentido, cabe ressaltar ainda que este estudo é considerado quantitativo, uma vez que a aplicação de questionários com perguntas objetivas possibilitará a tabulação dos dados.

\subsection{Coleta dos Dados}

Para a consecução deste trabalho, primeiramente foi identificada uma população de estudo formada por empresas localizadas no município de Belo Horizonte em Minas Gerais. A escolha do município para a execução da pesquisa se deu pelo fato de o município de Belo Horizonte se destacar por ser o maior polo empresarial do Estado de Minas Gerais (FIEMG, 2011) e a maior população do Estado, estimada em 2.375.151 habitantes (IBGE, 2010).

As informações sobre as empresas situadas em Belo Horizonte foram obtidas por meio do Cadastro Industrial de Minas Gerais, que é uma publicação bienal editada pelo Sistema FIEMG - Federação das Indústrias do Estado de Minas Gerais, por intermédio do Centro Industrial e Empresarial de Minas Gerais (CIEMG). Das 139 empresas de médio e grande porte, 89 foram selecionadas como empresas que têm o potencial de gerar resíduos devido ao seu setor de atuação. Destas, 31 fizeram parte 
da amostra da pesquisa que é por conveniência, ou seja, são aquelas que concordaram em participar da pesquisa respondendo ao questionário.

\subsection{Instrumento de Coleta de Dados}

Inicialmente foi realizado o contato por telefone com o objetivo de explicar os objetivos da pesquisa e buscar a confiança dos respondentes para participarem. Na sequência, para a coleta dos dados foi utilizado o questionário, o qual foi enviado por e-mail ao gestores das áreas de meio ambiente, qualidade ou segurança do trabalho, conforme identificação.

Considerando os elementos teóricos que sustentam práticas gerenciais que convergem à ecoeficiência, foram selecionados pontos principais que pudessem direcionar a pesquisa a alcançar seus objetivos. Assim, inicialmente o instrumento de coleta de dados passou por um pré-teste presencial realizado com nove empresas participantes da amostra, na qual foram identificadas falhas entre as questões formuladas e as mesmas foram corrigidas para posterior aplicação via e-mail com as demais empresas. O pré-teste serviu também para identificar informações adicionais sobre as questões formuladas para apresentá-las como dados qualitativos da análise.

\section{APRESENTAÇÃO E ANÁLISE DOS RESULTADOS}

No presente resultado, estão contidas as respostas de 31 companhias de médio (65\%) e grande (35\%) porte no município de Belo Horizonte, que constituíram a amostragem desse estudo. Inicialmente são apresentadas algumas características das empresas da amostra para melhor conhecimento de setor, porte, quantidade de produtos produzidos e relação do controle de capital aplicado na empresa. O Gráfico 1 representa os setores das empresas da amostra:

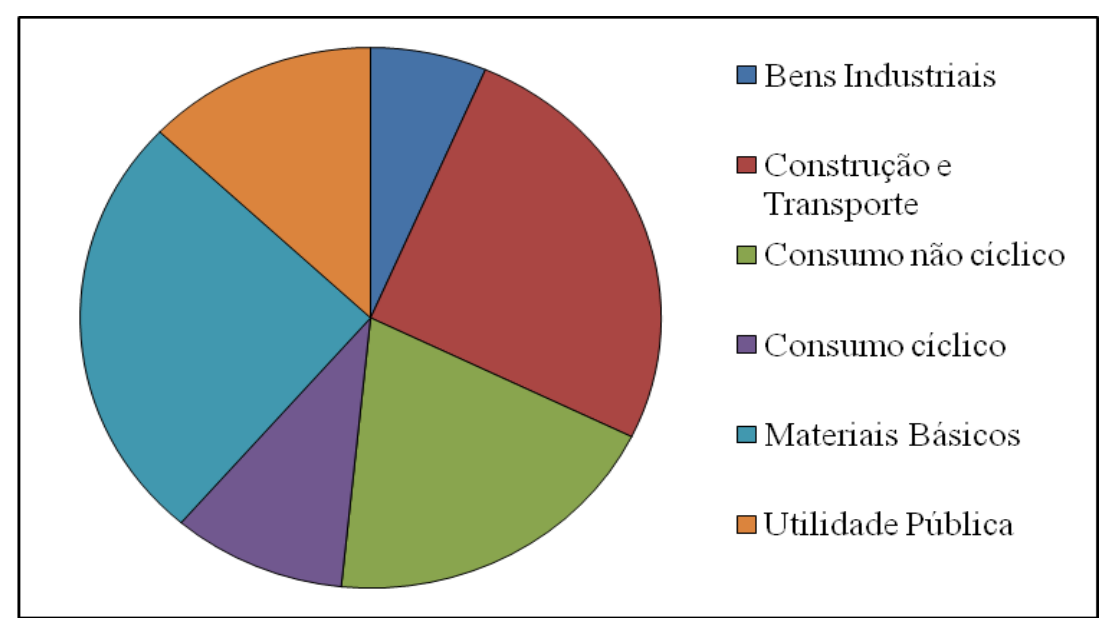

Gráfico 1: Setores das Empresas da Amostra

Fonte: Dados da pesquisa

REUNIR - Revista de Administração, Contabilidade e Sustentabilidade ISSN: 2237-3667 - Vol.3, nº 1, Jan./Abr., p. 80-102, 2013. 
Verifica-se por meio do gráfico 1 a diversidade de setores entre as empresas da amostra, conforme a classificação da BM\&FBOVESPA. O setor de materiais básicos é o mais representativo com oito empresas representando os subsetores de mineração, metalurgia, siderurgia, papel e celulose, embalagens, seguido de construção e transportes também com oito empresas. $\mathrm{O}$ consumo não cíclico representado por seis empresas constitui as atividades de agricultura, alimentos, bebidas. As quatro empresas do setor de utilidade pública atuam nos ramos de energia, saneamento e distribuição de gás. O consumo cíclico contém três empresas da área de vestuário, eletrodomésticos e jornais. Por fim, as duas empresas do setor de bens industriais representam as atividades de serviços diversos e máquinas e equipamentos.

Na sequência do levantamento de informações gerais sobre as empresas, foi verificada a composição do capital da empresa, no qual, verifica-se uma predominância do capital privado nacional em $77 \%$ das companhias da amostra, $9,6 \%$ de capital privado multinacional e $13 \%$ de capital misto. Não participa na amostra nenhuma empresa estatal. Verifica-se ainda que todas as empresas de capital privado multinacional e capital misto são de grande porte, totalizando sete. Dentre as empresas de capital privado nacional, predominam as de médio porte (19), seguido das empresas de grande porte (5).

Com relação aos resultados obtidos na pesquisa, inicialmente foi questionado às companhias se elas geravam resíduos por meio da sua atividade empresarial, e foi obtida uma resposta positiva de $100 \%$ das empresas. O objetivo do questionamento era validar a participação das companhias na pesquisa, uma vez que o gerenciamento de resíduos só é possível àquelas empresas que de fato têm a geração dos resíduos.

Depois se buscou conhecer os tipos de resíduos que eram gerados por essas empresas, conforme a classificação do CNTL do SENAI-RS (2003) e BRAGA (2010). Sendo possível escolher mais de uma opção conforme cada atividade empresarial, as empresas indicaram em média dois tipos de resíduos. Todas as empresas afirmaram que geram resíduos na forma sólida, $71 \%$ na forma líquida e $19 \%$ na forma gasosa (Gráfico 2). Uma empresa do setor alimentício informou ainda, gerar outros resíduos do tipo oleaginosos. 


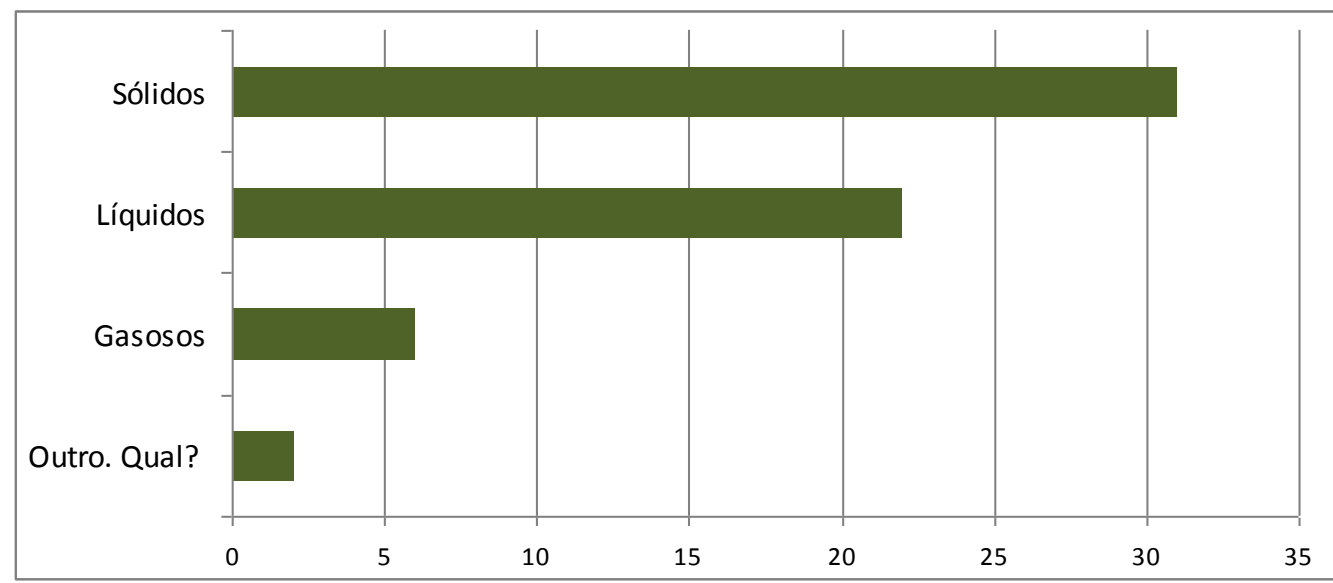

Gráfico 2: Tipos de resíduos gerados na atividade da empresa

Fonte: Dados da pesquisa

Com relação à periculosidade dos resíduos, foi questionado às empresas em conformidade com a Lei Federal $n^{-1}$ 12.305/2010 se os resíduos gerados eram perigosos ou não perigosos, sendo possível indicar as duas opções quando cabível. Foi constatado que 39\% das companhias geram resíduos considerados perigosos, o que indica que tais empresas necessitam observar a legislação ambiental vigente para saber como lidar com esses resíduos, e 74\% das empresas informaram que geram resíduos não perigosos, sendo que $13 \%$ da empresas indicaram gerar resíduos dos dois tipos. As três empresas do setor farmacêutico, por exemplo, indicaram a geração de resíduos perigosos e informaram que essa geração ocorre essencialmente em função do uso de produtos químicos na fabricação dos medicamentos. Outra empresa, do ramo de construção, informou que apenas uma pequena parte dos resíduos é do tipo perigoso e é originado principalmente da contaminação de equipamentos de proteção individual (EPI).

Buscando identificar se as empresas gerenciam seus resíduos, foi questionado sobre as formas de tratamento dadas a esses resíduos, deixando aberta a possibilidade do respondente explorar um pouco sobre o assunto em questão, conforme apresentado no Gráfico 3. Destaca-se que os tipos de tratamento de resíduos aqui abordados são considerados como formas de gerenciamento, sendo a coleta seletiva uma fase intermediária entre a geração e o gerenciamento.

É possível perceber por meio do Gráfico 3 que $71 \%$ das empresas utilizam a reciclagem como forma de gerenciar seus resíduos gerados na atividade da empresa, sendo esse procedimento o mais recorrente em comparação com os demais, tendo sido essa prática observada de forma institucionalizada entre as empresas pesquisadas, já que observa tanto evidências do estágio pré-institucional, o qual tem como característica principal a habitualização dos processos e a plena utilização por parte das empresas no estágio de total institucionalização (TOLBERT e ZUCKER, 1999). 
Ressalta-se que a reciclagem traz outros benefícios como a preservação dos recursos naturais, economia de energia, economia de transporte (FIRJAN, 2006; IBAM, 2001), podendo contribuir com o desenvolvimento sustentável. Com esses benefícios, em específico aqueles que trazem alguma economia de despesa, é possível identificar evidências de que as empresas estão em convergência com o processo de ecoeficiência do negócio. Destaca-se ainda que não necessariamente as companhias que informaram usar a reciclagem a fazem em sua própria empresa, pois há a possibilidade de que esse processo seja terceirizado. Foi percebido ainda que entre as empresas que geram resíduos perigosos (39\% da amostra), apenas uma entidade não faz reciclagem do resíduos, se destacando ainda, por realizar a coleta seletiva do mesmo.

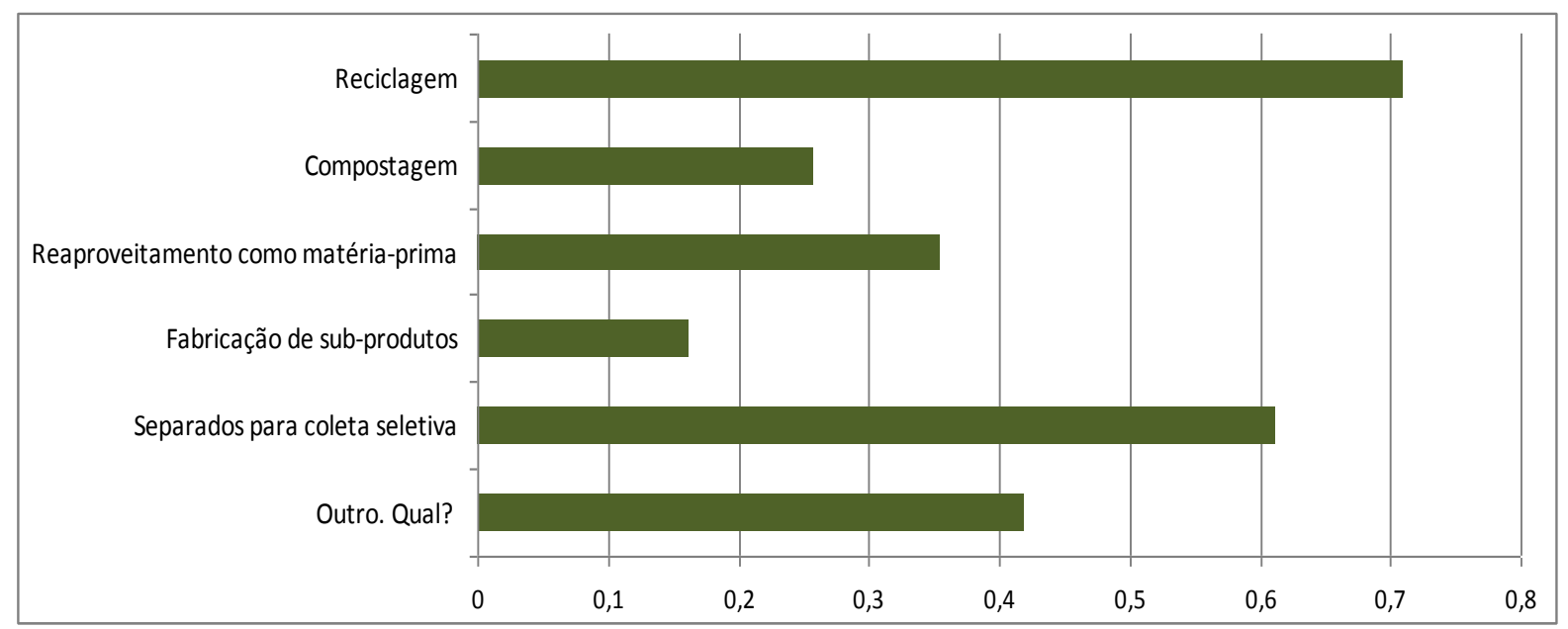

Gráfico 3: Tipos de tratamento dos resíduos usados pelas empresas da amostra Fonte: Dados da pesquisa

Em seguida, a coleta seletiva foi a segunda forma de tratamento dos resíduos citada pelas empresas da amostra (61\%). No entanto, apesar de representar mais que a metade da amostra, não seria considerada uma forma de gerenciamento de resíduos, e sim, uma etapa de transição existente entre a geração e o gerenciamento dos mesmos. Cerca de $35 \%$ das companhias informaram que reaproveitam os resíduos como matéria-prima, sendo o segundo nível estratégico de destinação dos resíduos que trata sobre a reutilização das sobras, conforme King et al (2006). Outras $26 \%$ fazem o uso da compostagem, processo natural de decomposição biológica de materiais orgânicos (IBAM, 2001).

Por outro lado, apenas $16 \%$ das empresas reutilizam os resíduos para a fabricação de subprodutos. Uma das empresas destacou que os resíduos são usados para fabricar coprodutos, que são diferentes dos subprodutos na medida em que têm uma geração de receita relevante para a empresa. 
Por fim, $42 \%$ das empresas afirmaram usar outros métodos para tratar seus resíduos, como, por exemplo, a incineração, usada por seis empresas, sendo três do setor farmacêutico. Tal processo é recorrente neste setor, pois se trata de produtos químicos que não podem ser descartados de outra forma devido a sua periculosidade. Também foram citadas pelas empresas como tratamento de resíduo as doações, destinados ao aterro, venda como sucata, devolução ao contratante/fornecedor, descontaminação, fertirrigação, tratamento de efluente e coprocessamento em fornos de cimento. Apenas uma empresa não optou por nenhum tipo de tratamento.

Na sequência da pesquisa, foi questionado às empresas sobre os princípios que a empresa leva em consideração para buscar melhorar a eficiência dos processos internos. Foi usado como referência os princípios levantados por WBCSD (2000b), os quais são atribuídos à melhoria da ecoeficiência e consequentemente ao desenvolvimento sustentável:

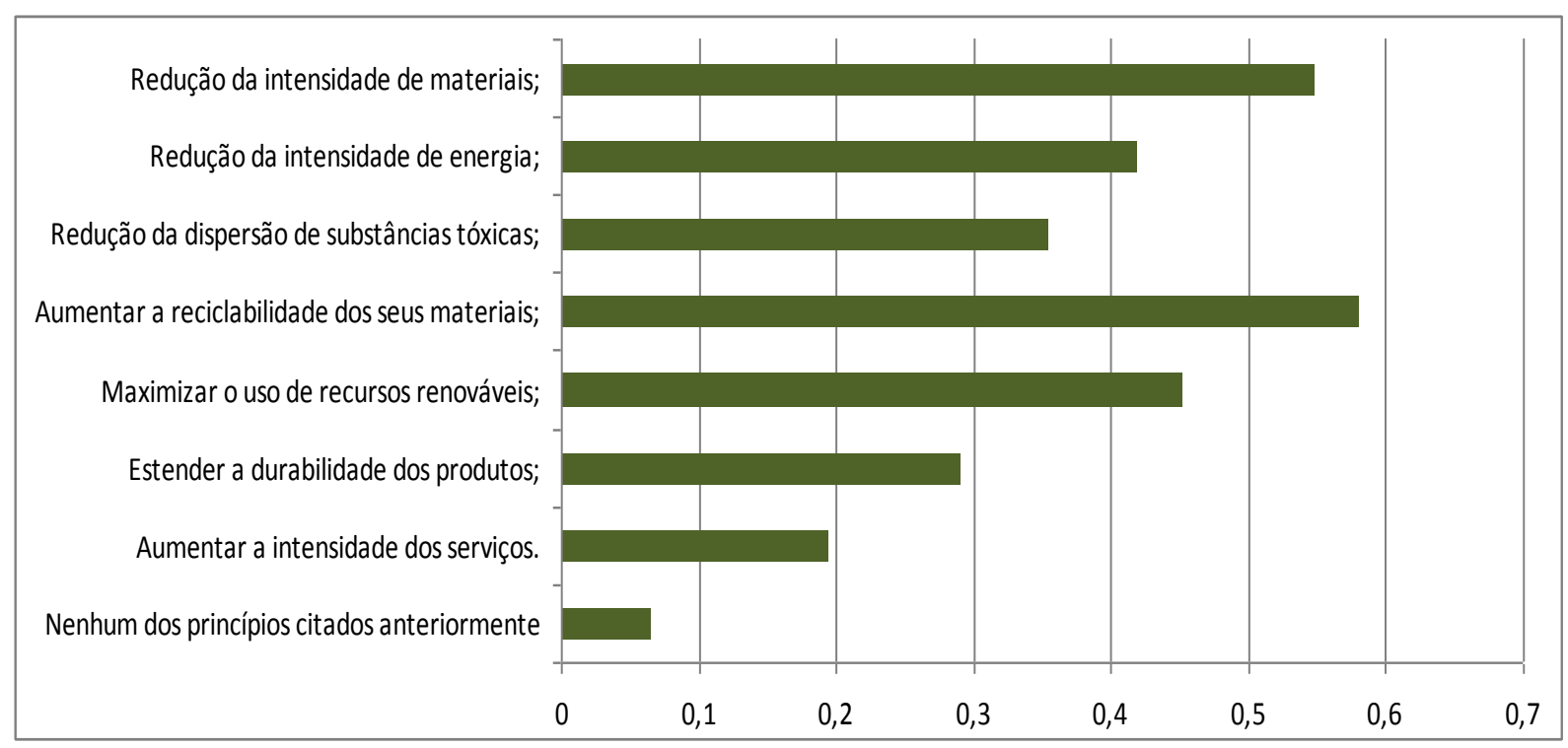

Gráfico 4: Princípios de eficiência observados pelas empresas

Fonte: Dados da pesquisa

Ressalta-se que, a implantação de práticas ambientais e de uma postura sustentável depende de diversos fatores internos à empresa, se destacando principalmente a convergência da missão da empresa com um forte ajuste à cultura organizacional (WEILER et al, 2005; WEBER et al, 2009; TINOCO e KRAEMER, 2008). Desta forma, os princípios propostos pelo WBCSD (2000b) trazem essa percepção, já que não são formas de tratamento ou gerenciamento de resíduos, mas sim parte de uma mudança organizacional ao se implantar tais valores na organização, o que pode contribuir com o processo de institucionalização de práticas ambientais. 
Desta forma, verifica-se que os princípios estão sendo considerados por $94 \%$ das empresas da amostra, ou seja, apenas duas empresas informaram não aplicá-los em busca de melhoria da eficiência dos seus processos. Os princípios mais citados pela maioria das empresas foram a busca pelo aumento da reciclabilidade dos seus materiais (58\%) e redução da intensidade dos materiais $(55 \%)$, sendo este último em concordância com o primeiro nível estratégico de destinação dos resíduos que trata da redução dos desperdícios atrelada também à elevação da durabilidade dos produtos, conforme King et al (2006).

Em seguida foram considerados a maximização do uso de recursos renováveis (45\%), redução da intensidade de energia (42\%), redução da dispersão de substâncias tóxicas (35\%), extensão da durabilidade dos produtos $(29 \%)$ e aumento da intensidade dos serviços (19\%). Destaca-se que este último princípio pode ter sido menos considerado pela questão de que a maioria das empresas da amostra não é prestadora de serviços. Os dados apresentados pelo Gráfico 4 indicam que há certa preocupação da empresas em observar os princípios de eficiência dos processos internos, em especial ao que se refere à geração e gestão de resíduos, no entanto, a habitualidade entre as empresas da amostra não apresenta uma relação suficientemente forte para evidenciar o processo de institucionalização nesse sentido.

\section{CONSIDERAÇÕES FINAIS}

O objetivo geral da pesquisa foi realizar uma análise empírica em empresas da região de Belo Horizonte que possuem potencial de geração de resíduos, a fim de observar evidências de institucionalização de suas práticas de gerenciamento desses resíduos, ou seja, quais procedimentos as empresas vêm adotando de forma sedimentada. Desta forma, inicialmente, verificou-se que dentre as formas de tratamento utilizadas pelas empresas, foi identificado que a reciclagem é o processo mais utilizado, seguido da coleta seletiva, que embora não se trate de gerenciamento do resíduo em si, é uma etapa intermediária para destinar o resíduo a algum tipo de gerenciamento específico.

Evidenciou-se também que apenas uma empresa não aplica nenhum tipo de tratamento aos resíduos, o que significa dizer que a maioria está de fato intencionada em gerenciar atividades no controle da geração e destinação dos resíduos. Percebeuse ainda que entre as empresas que geram resíduos perigosos, apenas uma não realiza reciclagem, no entanto, a mesma fornece o serviço de coleta seletiva. Tal constatação pode ser justificada pelas normas ambientais relacionadas com a geração de resíduos perigosos, a qual responsabilidade o gerador do resíduo pela sua adequada destinação.

Essas questões trouxeram uma forte evidência de que essas empresas possuem um padrão consciente de gestão de resíduos e uma preocupação em reutilizá-los 
como uma economia de custos ou gerar receita com a venda de subprodutos ou sucatas, tendo sido essa prática observada de forma institucionalizada entre as empresas pesquisadas.

Ao questionar sobre os princípios que a empresa leva em consideração para buscar melhorar a eficiência dos processos internos, novamente foi constatado o aumento da reciclabilidade dos materiais como o item de maior destaque, juntamente com a redução da intensidade de materiais. Percebe-se que a prática de reciclagem visando reduzir a geração de resíduos e de materiais que não podem ser reciclados como a mais sedimentada na prática empresarial.

Baseado nos achados da pesquisa, bem como na revisão de literatura que observa que a instituição é um conjunto de rotinas desempenhadas de forma habitual por um grupo de indivíduos, constata-se que as empresas da amostra estão claramente em um progresso moderado de sedimentação de práticas voltadas para a sustentabilidade empresarial, no que se refere ao gerenciamento dos resíduos, no entanto, a institucionalização dessas práticas ainda não se encontra em funcionamento pleno, tendo em vista que algumas empresas demonstraram que ainda não estão integralmente comprometidas.

Ressalta-se como limitação da pesquisa o número e a limitação geográfica da pesquisa e sugere-se para pesquisas futuras a ampliação da amostra.

\section{REFERÊNCIAS}

ABNT - Associação Brasileira de Normas Técnicas. NBR ISO 14001 - Sistemas da gestão contábil - Requisitos como orientação para uso. 27p, 2004.

BARBIERI, José Carlos. Gestão Ambiental empresarial: conceitos, modelos e instrumentos. 2 ed. São Paulo: Saraiva, 2007.

BEUREN, Ilse Maria (organizadora e colaboradora). Como elaborar trabalhos monográficos em Contabilidade - Teoria e Prática. 3 ed. São Paulo: Atlas, 2008.

BRAGA, Célia (organizadora). Contabilidade Ambiental. Ferramenta para a Gestão da Sustentabilidade. São Paulo: Atlas, 2010.

BRASIL. Lei 12.305. Institui a Política Nacional de Resíduos Sólidos; altera a Lei no 9.605, de 12 de fevereiro de 1998; e dá outras providências. Brasília, 02 de Ago de 2010. Disponível em: http://www.planalto.gov.br/ccivil 03/ Ato20072010/2010/Lei/L12305.htm. Acesso em 13 mar. 2011. 
BRUNDTLAND, G. H.; EHRLICH, P.; GOLDEMBERG, J.; HANSEN, J.; LOVINS, A.; LIKENS, G.; LOVELOCK, J.; MANABE, S.; MAY, B.; MOONEY, H.; ROBERT, K-H.; SALIM, E.; SATO, G.; SOLOMON, S.; STERN, N.; SWAMINATHAN, MS.; WATSON, B. Environment and Development Challenges: The Imperative to Act. Barefoot College, Conservation International, International institute of Environment and Development, and International Union for the Conservation of Nature. Disponível em: http:/qualenergia.it/sites/default/files/articolo-doc/Blue-PlanetSynthesis-Paper-for-UNEP.pdf. Acesso em: mar. 2012.

BURRIT, Roger L.; SAKA, Chica. Environmental management accounting applications and eco-efficiency: case studies from Japan. Journal of Cleaner Production, 14, p. 1262-1275, 2006.

CHAROUX, O. M. G. Metodologia: processo de produção, registro e relato do conhecimento. 3를 Ed. São Paulo: DVS Editora, 2006.

FERREIRA, Aracéli de Sousa. Contabilidade Ambiental - Uma informação para o desenvolvimento sustentável. 2 ed. São Paulo: Atlas, 2007.

FIEMG. Federação das Indústrias do Estado de Minas Gerais. Disponível em: http://www.fiemg.com.br/Cadastro Industrial MG/Anonimo/Abrangencia lst.aspx. Acesso em: mai. 2011.

FIRJAN, Sistema. Christianne Arraes Maroun. Manual de Gerenciamento de Resíduos: Guia de procedimento passo a passo. 2 ed. Rio de Janeiro: GMA, 2006.

FRISHKNECHT, Rolf. LCI modelling approaches applied on recycling of materials in view of environmental sustainability, risk perception and eco-efficiency. Int J Life Cycle Assess, v. 15, p. 666-671, 2010.

GIL, Antônio Carlos. Métodos e técnicas de pesquisa social. 5 ed. São Paulo: Atlas, 1999.

GUERREIRO, Reinaldo; FREZATTI, Fábio; CANSADO, Tânia. Em busca de um melhor entendimento da contabilidade gerencial através da integração de conceitos de psicologia, cultura organizacional e teoria institucional. Revista Contabilidade e Finanças, USP - São Paulo. Edição Comemorativa, p. 7 - 21, Setembro de 2006.

HEDIGER, Werner. Towards an Ecological Economics of Sustainable Development. Sustainable Development, v. 5, p. 101-109, 1997. 
HOFFRÉN, Jukka; APAJALAHTI, Eeva-Lotta. Emergent Eco-efficiency paradigm in Corporate Environment Management. Sustainable Development, V. 17, p. 233-243, 2009.

HU, Tung Lai; SHEU, Jiuh-Biing; HUANG, Kuan-Hsiung. A reverse logistics cost minimization model for the treatment of hazardous wastes. Transportation Research Part E, Elsevier, v. 38, p. 457-473, 2002.

IBAM: Instituto Brasileiro de Administração Municipal. José Henrique Penido Monteiro ...[et al.]; coordenação técnica Victor Zular Zveibil. Manual de Gerenciamento Integrado de resíduos sólidos. Rio de Janeiro: IBAM, 193 p., 2001.

KING, Andrew M.; BURGESS, Stuart C.; IJOMAH, Winnie; McMAHON, Chris A. Reducing waste: Repair, Recondicion, Remanufacture or Recycle? Sustainable Development. V. 14, p. 257-267, 2006.

KRAEMER, Maria Elisabeth Pereira. Como quantificar e contabilizar os resíduos industriais. Contabilidade e Informação, Ijuí Editora Unijuí, ano 9, no 24, p. 31-40, jan/jun. 2006.

LILJA, Raimo. From waste prevention to promotion of material efficiency: change of discourse in the waste policy of Finland. Journal of Cleaner Production, v. 17, p. 129 à 136, 2009.

MAHER, M. Contabilidade de Custos - Criando Valor Para a Administração. São Paulo: Atlas, 2001.

MEMON, Mushtaq Ahmed. Integrated solid waste management based on the $3 R$ approach. J Mater Cycles Waste Manag,v. 12, p. 30 à 40, 2010.

NASCIMENTO, Tereza Cristina F do; MOTHÉ, Cheila Gonçalves. Gerenciamento de resíduos sólidos industriais. Revista Analytica, Fevereiro/Março 2007, №27.

NOBRE, Marcos; AMAZONAS, Maurício de Carvalho. Desenvolvimento Sustentável: A institucionalização de um conceito. In: AMAZONAS, Maurício de Carvalho. O desenvolvimento sustentável e a perspectiva das teorias econômicas "institucionais". Brasília: Edições IBAMA, 2002.

PAIVA, Paulo Roberto de. Contabilidade Ambiental. Evidenciação dos gastos ambientais com transparência e focada na prevenção. São Paulo: Atlas, 2009. 
PONGRÁCZ, Eva. Through waste prevention towards corporate sustainability: Analysis of the concept of waste and review of the attitudes towards waste prevention. Sustainable Development. V. 17, p. 92-101, 2009.

PRAKASH, Aseem. A new-institutionalist perspective on ISO 14000 and responsible care. Business Strategy and the Environment, v.8, p. 322-335, 1999.

SEIFFERT, Mari Elizabete Bernardini. ISO 14001 Sistemas de Gestão Ambiental. Implantação objetiva e econômica. 2 ed. São Paulo: Atlas, 2006.

SENAIS-RS. Questões Ambientais e produção mais limpa. Porto Alegre, UNIDO, UNEP, Centro Nacional de Tecnologias Limpas SENAI, 2003. 126 p. il. (Série Manuais de Produção mais Limpa).

SISINNO, Cristina Lúcia Silveira; MOREIRA, Josina Costa. Ecoeficiência: um instrumento para redução da geração de resíduos e desperdícios em estabelecimentos de saúde. Caderno de Saúde Pública, V. 21(6), p. 1893-1900, nov/dez, 2005.

TINOCO, João E. Prudêncio; KRAEMER, Maria Elisabeth Pereira. Contabilidade e gestão ambiental. 2 ed. Atlas: São Paulo, 2008.

TOLBERT, P. S.; ZUCKER, L. G. A instrumentalização da teoria institucional. In: CLEGG, S. R.; HARDY, C.; NORD, W. R. (Orgs.) Handbook de estudos organizacionais. São Paulo: Atlas, 1999.

VELLANI, Cassio Luiz; RIBEIRO, Maísa de Souza. Sistema Contábil para gestão da ecoeficiência empresarial. Revista Contabilidade \& Finanças, USP. V. 20, n. 49, p. 25-43, jan/abr 2009. São Paulo.

VIEGAS, Cláudia; FRACASSO, Edi Madalena. Capacidade Tecnológica e Gestão de Resíduos em Empresas de Calçados do Vale do Sinos: Estudo de Dois Casos. RAC, v.2, n.2, Maio/Ago. 1998: 41-62.

VILLIERS, Charl de; STADEN, Chris J. van. Shareholders' requirements for corporate environmental disclosures: A cross country comparison. The British Accounting Review, n. 42, p. 227-240. 2010. 
WBCSD (World Business Council for Sustainable Development).Eco-efficiency. Creating more value with less impact. Conches: Geneva, 2000a.

Measuring eco-efficiency. A guide to reporting company performance. Conches: Geneva, Switzerland, 2000b.

WCED (World Comission on Environmental and Development. Our Common Future. 1987. Disponível em: http://www.un-documents.net/wced-ocf.htm. Acesso em: mai. 2011.

WEBER, Shana; BOOKHART, Davis; NEWMAN, Julie. Institutionalizing CampusWide Sustainability: A programmatic aproch. Mary Ann Liebert, Inc. Vol. 2 № 3, June, 2009.

WEILER, Ernest D.; ANDREWS, Larry S.; REINERT, Kevin H.; MAHER, Kathleen V. Institutionalizing Sustainability Concepts: Some Decision Support Tools. Environmental Quality Management. Spring, p. 1-8, 2005.

ZAMORANO, M.; GRINDLAY, A.; MOLERO, E.; RODRÍGUEZ, M.I. Diagnosis and proposals for waste management in industrial areas in the service sector: case study in the metropolitan area of Granada (Spain). Journal of Cleaner Production, v. 19, p. 1946 á 1955, 2011. 